\title{
The incidence and most common levels of thoracic degenerative disc pathologies
}

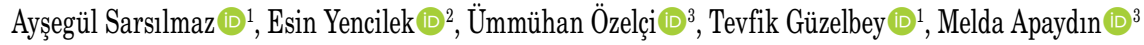 \\ ${ }^{1}$ Department of Radiology, Yeditepe Medical School, İstanbul, Turkey \\ ${ }^{2}$ Department of Radiology, University of Health Sciences, Haydarpaşa Numune Training and Research Hospital, İstanbul, Turkey \\ ${ }^{3}$ Department of Radiology, University of Health Sciences, Katip Çelebi Medical School Atatürk Training and Research Hospital, İzmir, Turkey \\ Received: January 03, 2017 Accepted: June 15, 2017 Published online: May 16, 2018
}

\begin{abstract}
Objectives: In this study, we aimed to describe and characterize the incidence of thoracic degenerative disc pathologies, bulging/herniation, and the most common affected levels.

Patients and methods: Between January 2008 and May 2012, a total of 195 patients (109 females, 86 males; mean age 43.5 years; range, 15 to 74 years) who were admitted with the complaint of dorsalgia and underwent magnetic resonance imaging (MRI) of the thoracic vertebral column were included in the study. Data including MRI findings, endplate and disc degeneration, disc height loss, bulging, and disc herniation were retrospectively analyzed.

Results: Of 3,348 patients, 195 patients had disc bulging/herniation. When 12 levels in 195 cases were taken into consideration, disc pathologies were found in 412 (18\%) levels among the total of 2,340 intervertebral disc levels. Bulging was present in 11\% (244/2,340) of the levels. Disc herniation was present in $7 \%(168 / 2,340)$ of the levels. The most commonly affected site was $\mathrm{T}_{7-8}$, followed by $\mathrm{T}_{8-9}$ and $\mathrm{T}_{11-12}$.

Conclusion: Thoracic disc pathologies are still a significant diagnostic challenge. Our study results show that the incidence of these pathologies is higher than expected.
\end{abstract}

Keywords: Bulging; dorsalgia; magnetic resonance imaging; thoracic disc herniation.

Thoracic disc bulgings/herniations are relatively uncommon, compared to lumbar and cervical disc pathologies. It is estimated that only 0.25 to $1 \%$ of all disc herniations take place in the thoracic region. ${ }^{[1]}$ Although uncommon, it can be challenging to diagnose thoracic disease accurately, particularly thoracic disc herniation, which is a significant problem, since it can mimic several medical conditions and is often misdiagnosed as a cardiac, abdominal, gastrointestinal, neoplastic, or a demyelinating disease. ${ }^{[2]}$ In thoracic disc herniation, dorsalgia of gradual onset may accompany some degree of myelopathy or sensory deficits and can reach disabling levels. ${ }^{[3]}$

Since dorsalgia is a highly common manifestation, making the differential diagnosis with various benign or more serious conditions is difficult in such settings. ${ }^{[4-7]}$ The current diagnostic method of choice is magnetic resonance imaging (MRI), which is considered to improve this assessment in thoracic disc degenerative pathologies. ${ }^{[8,9]}$ With MRI, the degenerative disc pathologies that would remain undetected can be diagnosed..$^{[10]}$

In this study, we aimed to determine the incidence of thoracic disc bulgings/herniations at single or multiple levels and to evaluate the most common levels of the pathologies.

\section{PATIENTS AND METHODS}

After obtaining the approval of the Institutional Ethics Committee, the study was retrospectively performed by chart review. A written informed consent was obtained from each patient. The study was conducted in accordance with the principles of 
the Declaration of Helsinki. Between January 2008 and May 2012, a preliminary database of a total of 3,348 patients was created. The inclusion criteria of the study were as follows: patients aged 15 years and over, patients admitted with the complaint of dorsalgia and patients who were scanned via MRI of the thoracic vertebral column at our hospital. The exclusion criteria were as follows: patients who had a chronic metabolic disorder, suspicion of infection, presence of a compression fracture, acute trauma, and malignancy in their medical history. Patients with prominent kyphosis and who had rotoscoliosis were also excluded.

The cases included in the study were divided into five age groups of 15-30,31-40,41-50, 51-60, and 61 years and over. The data were recorded regarding the number of the intervertebral disc units.

The MRI images were assessed by a neuroradiologist experienced in spine MRI at two different times. Finally, findings were evaluated with regard to consensus of two separate assessments by a single radiologist.

Disc pathologies were defined as updated lumbar disc nomenclature. ${ }^{[11]}$

The cases were evaluated regarding the presence of disc pathologies: herniation, bulging, protrusion, and extrusion, sequestration, the degeneration of the disc and the endplate, the disc height loss, and the Schmorl nodes. The results of the two separate evaluations were compared and a consensus was reached.

\section{RESULTS}

Following the assessment of 3,348 patients in the preliminary database, 195 (5.82\%) patients (109 females, 86 males; mean age 43.5 years; range, 15 to 74 years) had disc bulging/herniation (2,340 disc levels). Forty patients belonged to the age group of $15-30$ years, 44 patients to $31-40$ years, 52 patients to $41-50$ years and 27 patients to 51-60 years; 32 patients were aged 61 years or over.

$\mathrm{T}_{2}$ and $\mathrm{T}_{1}$-weighted sagittal and $\mathrm{T}_{2}$-weighted axial images of 195 patients were obtained with the $1.5 \mathrm{~T}$ Philips InterraMRI system in our hospital. In all cases, $\mathrm{T}_{1} \mathrm{~W}$ (TR: 562 TE: 18 FOV: 250), $\mathrm{T}_{2} \mathrm{~W}$ (TR: 3470, TE: 80, FOV: 250) sagittal, $\mathrm{T}_{2} \mathrm{~W}$ (TR: 5244, TE: 100, FOV: 250) axial sequences were obtained via the MRI technique.

The results for the disc bulging/herniation in each thoracic intervertebral level are shown in numbers according to the age groups in Table 1.

Table 1. The frequency distribution of the findings regarding the levels of disc pathologies (bulging, herniation) according to age groups

\begin{tabular}{|c|c|c|c|c|c|c|c|c|c|c|c|c|c|c|}
\hline \multirow{4}{*}{ Level } & \multicolumn{14}{|c|}{ Age (year) } \\
\hline & \multicolumn{2}{|c|}{$\begin{array}{l}15-30 \\
(\mathrm{n}=40)\end{array}$} & \multicolumn{2}{|c|}{$\begin{array}{l}31-40 \\
(\mathrm{n}=44)\end{array}$} & \multicolumn{2}{|c|}{$\begin{array}{l}41-50 \\
(\mathrm{n}=52)\end{array}$} & \multicolumn{2}{|c|}{$\begin{array}{l}51-60 \\
(\mathrm{n}=27)\end{array}$} & \multicolumn{2}{|c|}{$\begin{array}{c}\geq 61 \\
(\mathrm{n}=32)\end{array}$} & \multicolumn{4}{|c|}{$\begin{array}{c}\text { Total patient } \\
(\mathrm{n}=195)(\text { level number }=412)\end{array}$} \\
\hline & \multirow{2}{*}{$\frac{\mathrm{B}}{\mathrm{n}}$} & \multirow{2}{*}{$\frac{\mathrm{H}}{\mathrm{n}}$} & \multirow{2}{*}{$\frac{\mathrm{B}}{\mathrm{n}}$} & \multirow{2}{*}{$\frac{\mathrm{H}}{\mathrm{n}}$} & \multirow{2}{*}{$\frac{\mathrm{B}}{\mathrm{n}}$} & \multirow{2}{*}{$\frac{\mathrm{H}}{\mathrm{n}}$} & \multirow{2}{*}{$\frac{\mathrm{B}}{\mathrm{n}}$} & \multirow{2}{*}{$\frac{\mathrm{H}}{\mathrm{n}}$} & \multirow{2}{*}{$\frac{\mathrm{B}}{\mathrm{n}}$} & \multirow{2}{*}{$\frac{\mathrm{H}}{\mathrm{n}}$} & \multicolumn{2}{|c|}{ B } & \multicolumn{2}{|c|}{$\mathrm{H}$} \\
\hline & & & & & & & & & & & $\mathrm{n}$ & $\%$ & $\mathrm{n}$ & $\%$ \\
\hline $\mathrm{T}_{1-2}$ & 0 & 1 & 0 & 2 & 1 & 0 & 0 & 0 & 1 & 0 & 2 & 0.4 & 3 & 0.7 \\
\hline $\mathrm{T}_{2-3}$ & 1 & 1 & 2 & 1 & 2 & 2 & 1 & 1 & 1 & 1 & 7 & 1.69 & 6 & 1.45 \\
\hline $\mathrm{T}_{3-4}$ & 3 & 1 & 3 & 2 & 1 & 2 & 0 & 0 & 2 & 0 & 9 & 2.18 & 5 & 1.2 \\
\hline $\mathrm{T}_{4-5}$ & 1 & 0 & 4 & 1 & 4 & 3 & 0 & 0 & 0 & 0 & 9 & 2.18 & 4 & 0.9 \\
\hline $\mathrm{T}_{5-6}$ & 4 & 4 & 7 & 2 & 4 & 3 & 2 & 1 & 3 & 2 & 20 & 4.8 & 12 & 2.9 \\
\hline $\mathrm{T}_{6-7}$ & 6 & 3 & 2 & 3 & 4 & 5 & 2 & 2 & 3 & 4 & 17 & 4.12 & 17 & 4.12 \\
\hline $\mathrm{T}_{7-8}$ & 15 & 9 & 15 & 5 & 10 & 12 & 5 & 6 & 8 & 5 & 53 & 12.8 & 37 & 8.9 \\
\hline $\mathrm{T}_{8-9}$ & 6 & 6 & 6 & 4 & 8 & 9 & 6 & 3 & 7 & 7 & 33 & 8 & 29 & 7 \\
\hline $\mathrm{T}_{9-10}$ & 4 & 2 & 3 & 2 & 5 & 4 & 4 & 2 & 6 & 4 & 22 & 5.3 & 14 & 3.3 \\
\hline $\mathrm{T}_{10-11}$ & 5 & 1 & 2 & 2 & 5 & 3 & 6 & 2 & 10 & 2 & 28 & 6.7 & 10 & 2.4 \\
\hline $\mathrm{T}_{11-12}$ & 6 & 4 & 4 & 8 & 6 & 6 & 7 & 3 & 10 & 2 & 33 & 8 & 23 & 5.5 \\
\hline $\mathrm{T}_{12}-\mathrm{L}_{1}$ & 2 & 1 & 1 & 1 & 3 & 4 & 2 & 1 & 4 & 0 & 12 & 2.9 & 7 & 1.6 \\
\hline \multirow[t]{2}{*}{ Total } & 53 & 33 & 49 & 34 & 53 & 53 & 35 & 20 & 55 & 27 & 245 & 59.4 & 167 & 40.6 \\
\hline & & & & & & & & & & & \multicolumn{2}{|c|}{ (total bulging levels) } & \multicolumn{2}{|c|}{$\begin{array}{l}\text { (total herniation } \\
\text { levels) }\end{array}$} \\
\hline
\end{tabular}




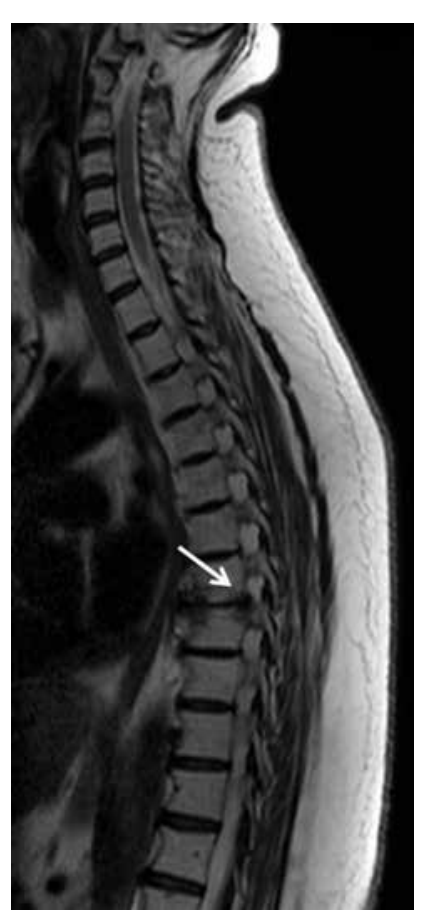

Figure 1. Sagittal $\mathrm{T}_{2}$-weighted magnetic resonance image showing disc height loss, endplate and disc degeneration, left paracentral disc herniation (arrow).

When 12 levels in 195 cases were taken into consideration, disc bulging/herniation were determined in 412 (18\%) levels among the total of

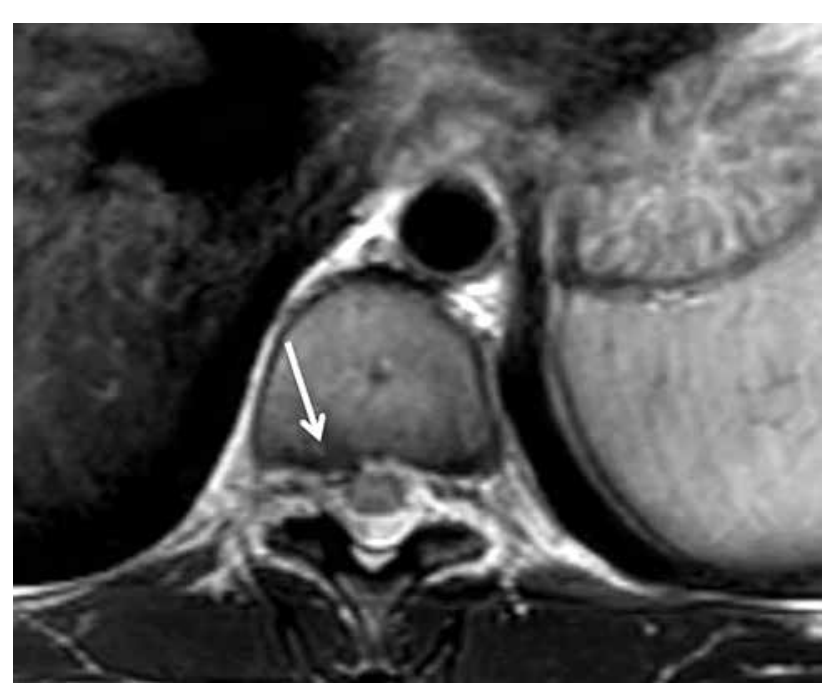

Figure 2. Axial $\mathrm{T}_{2}$-weighted magnetic resonance image showing right paracentral disc herniation; protrusion (arrow).

2,340 intervertebral disc levels. Bulging was present in $11 \%(245 / 2,340)$ of the levels. The most commonly affected site was $\mathrm{T}_{7-8}$, followed by $\mathrm{T}_{8-9}$ and $\mathrm{T}_{11-12}$. The level that bulging was least common was $\mathrm{T}_{1-2}$ with $0.1 \%$ incidence $(2 / 2,340)$. Disc herniation was present in $7 \%(167 / 2,340)$ of the levels. The most commonly affected site was $\mathrm{T}_{7-8}$, followed by $\mathrm{T}_{8-9}$ and $\mathrm{T}_{11-12}$. Figure 1 ( $\mathrm{T}_{2}$-weighted sagittal image) shows left paracentral disc herniation, endplate degeneration and disc height loss at level $\mathrm{T}_{7-8}$. Figure $2\left(\mathrm{~T}_{2}\right.$-weighted axial image) shows right paracentral disc herniation at level $\mathrm{T}_{10-11}$. The level that disc herniation was the

Table 2. The distribution of disc pathologies identified in magnetic resonance imaging according to intervertebral disc levels

\begin{tabular}{|c|c|c|c|c|c|c|c|}
\hline \multirow{3}{*}{ Disc level } & \multicolumn{2}{|c|}{ Bulging } & \multicolumn{3}{|c|}{ Herniation } & \multirow{2}{*}{\multicolumn{2}{|c|}{ Total level }} \\
\hline & Bulging & Asymmetric & Protrusion & Extrusion & Sequestration & & \\
\hline & $\mathrm{n}$ & $\mathrm{n}$ & $\mathrm{n}$ & $\mathrm{n}$ & $\mathrm{n}$ & $\mathrm{n}$ & $\%$ \\
\hline $\mathrm{T}_{1-2}$ & 2 & $\varnothing$ & 3 & $\varnothing$ & $\varnothing$ & 5 & 1.2 \\
\hline $\mathrm{T}_{2-3}$ & 6 & 1 & 5 & 1 & $\varnothing$ & 13 & 3.1 \\
\hline $\mathrm{T}_{3-4}$ & 7 & 2 & 5 & $\varnothing$ & $\varnothing$ & 14 & 3.3 \\
\hline $\mathrm{T}_{4-5}$ & 8 & 1 & 4 & $\varnothing$ & $\varnothing$ & 13 & 3.1 \\
\hline $\mathrm{T}_{5-6}$ & 20 & $\varnothing$ & 10 & 2 & $\varnothing$ & 32 & 7.7 \\
\hline $\mathrm{T}_{6-7}$ & 16 & 1 & 17 & $\varnothing$ & $\varnothing$ & 34 & 8.2 \\
\hline $\mathrm{T}_{7-8}$ & 50 & 3 & 33 & 3 & 1 & 90 & 21.8 \\
\hline $\mathrm{T}_{8-9}$ & 29 & 4 & 29 & $\varnothing$ & $\varnothing$ & 62 & 15 \\
\hline $\mathrm{T}_{9-10}$ & 21 & 1 & 13 & 1 & $\varnothing$ & 36 & 8.7 \\
\hline $\mathrm{T}_{10-11}$ & 26 & 2 & 9 & 1 & $\varnothing$ & 38 & 9.2 \\
\hline $\mathrm{T}_{11-12}$ & 29 & 4 & 21 & 2 & $\varnothing$ & 56 & 13.5 \\
\hline $\mathrm{T}_{12}-\mathrm{L}_{1}$ & 10 & 2 & 7 & $\varnothing$ & $\varnothing$ & 19 & 4.6 \\
\hline Total & 224 & 21 & 156 & 10 & 1 & 412 & 99.4 \\
\hline
\end{tabular}


Table 3. The frequency distribution of disc levels according to the cases with single and multi-level pathologies

\begin{tabular}{|c|c|c|c|c|c|c|c|c|c|c|c|c|}
\hline \multirow{4}{*}{ Disc level } & \multicolumn{4}{|c|}{ Single level } & \multicolumn{8}{|c|}{ Multi level } \\
\hline & & & & & & & & & & lging & niat & \\
\hline & \multicolumn{2}{|c|}{ Bulging } & \multicolumn{2}{|c|}{ Herniation } & \multicolumn{2}{|c|}{ Bulging only } & \multicolumn{2}{|c|}{ Herniation only } & \multicolumn{2}{|c|}{ Bulging } & \multicolumn{2}{|c|}{ Herniation } \\
\hline & $\mathrm{n}$ & $\%$ & $\mathrm{n}$ & $\%$ & $\mathrm{n}$ & $\%$ & $\mathrm{n}$ & $\%$ & $\mathrm{n}$ & $\%$ & $\mathrm{n}$ & $\%$ \\
\hline $\mathrm{T}_{1-2}$ & 0 & & 2 & & 0 & & 1 & & 1 & & 1 & \\
\hline $\mathrm{T}_{2-3}$ & 2 & & 2 & & 3 & & 1 & & 2 & & 3 & \\
\hline $\mathrm{T}_{3-4}$ & 1 & & 1 & & 6 & & 3 & & 2 & & 1 & \\
\hline $\mathrm{T}_{4-5}$ & 1 & & 0 & & 4 & & 2 & & 3 & & 3 & \\
\hline $\mathrm{T}_{5-6}$ & 2 & & 3 & & 13 & & 4 & & 6 & & 5 & \\
\hline $\mathrm{T}_{6-7}$ & 2 & & 2 & & 8 & & 12 & & 7 & & 3 & \\
\hline $\mathrm{T}_{7-8}$ & 16 & & 15 & & 26 & & 22 & & 6 & & 4 & \\
\hline $\mathrm{T}_{8-9}$ & 5 & & 3 & & 24 & & 19 & & 6 & & 5 & \\
\hline $\mathrm{T}_{9-10}$ & 4 & & 3 & & 16 & & 10 & & 2 & & 1 & \\
\hline $\mathrm{T}_{10-11}$ & 4 & & 0 & & 17 & & 7 & & 7 & & 3 & \\
\hline $\mathrm{T}_{11-12}$ & 8 & & 6 & & 22 & & 5 & & 5 & & 10 & \\
\hline $\mathrm{T}_{12}-\mathrm{L}_{1}$ & 4 & & 1 & & 8 & & 2 & & 2 & & 2 & \\
\hline Total & 49 & 11.8 & 1 & 9.2 & 8 & 35.6 & 2 & 21.3 & 49 & 11.8 & 41 & 9.9 \\
\hline
\end{tabular}

least common was $\mathrm{T}_{1-2}$ with $0.1 \%$ incidence $(3 / 2,340)$. The disc pathologies identified by MRI are shown in detail in Table 2.
The total number of cases with single-level disc pathology was 80 (42 with bulging, and 38 with herniation). When 42 cases with single-level bulging

Table 4. The frequency distribution of the Schmorl nodes, endplate degeneration, disc height loss, according to the levels

\begin{tabular}{|c|c|c|c|c|c|c|c|}
\hline \multirow[t]{2}{*}{ Endplate level } & \multicolumn{2}{|c|}{ Number of Schmorl nodes } & \multirow[t]{2}{*}{ Disc level } & \multicolumn{2}{|c|}{$\begin{array}{l}\text { Endplate degeneration } \\
\quad \text { (level numbers) }\end{array}$} & \multicolumn{2}{|c|}{$\begin{array}{l}\text { Disc height loss } \\
\text { (level numbers) }\end{array}$} \\
\hline & $\mathrm{n}$ & $\%$ & & $\mathrm{n}$ & $\%$ & $\mathrm{n}$ & $\%$ \\
\hline $\begin{array}{l}\mathrm{T}_{1} \text { inferior } \\
\mathrm{T}_{2} \text { superior }\end{array}$ & 0 & & $\mathrm{~T}_{1-2}$ & 0 & & 0 & \\
\hline $\begin{array}{l}T_{2} \text { inferior } \\
T_{3} \text { superior }\end{array}$ & 0 & & $\mathrm{~T}_{2-3}$ & 1 & & 0 & \\
\hline $\begin{array}{l}\mathrm{T}_{3} \text { inferior } \\
\mathrm{T}_{4} \text { superior }\end{array}$ & $\begin{array}{l}1 \\
1\end{array}$ & & $\mathrm{~T}_{3-4}$ & 2 & & 1 & \\
\hline $\begin{array}{l}\mathrm{T}_{4} \text { inferior } \\
\mathrm{T}_{5} \text { superior }\end{array}$ & $\begin{array}{l}3 \\
4\end{array}$ & & $\mathrm{~T}_{4-5}$ & 8 & & 5 & \\
\hline $\begin{array}{l}T_{5} \text { inferior } \\
T_{6} \text { superior }\end{array}$ & $\begin{array}{l}4 \\
5\end{array}$ & & $\mathrm{~T}_{5-6}$ & 12 & & 7 & \\
\hline $\begin{array}{l}\mathrm{T}_{6} \text { inferior } \\
\mathrm{T}_{7} \text { superior }\end{array}$ & $\begin{array}{c}11 \\
6\end{array}$ & & $\mathrm{~T}_{6-7}$ & 18 & & 7 & \\
\hline $\begin{array}{l}T_{7} \text { inferior } \\
T_{8} \text { superior }\end{array}$ & $\begin{array}{l}31 \\
23\end{array}$ & & $\mathrm{~T}_{7-8}$ & 64 & & 52 & \\
\hline $\begin{array}{l}\mathrm{T}_{8} \text { inferior } \\
\mathrm{T}_{9} \text { superior }\end{array}$ & $\begin{array}{l}37 \\
30\end{array}$ & & $\mathrm{~T}_{8-9}$ & 70 & & 60 & \\
\hline $\begin{array}{l}\mathrm{T}_{9} \text { inferior } \\
\mathrm{T}_{10} \text { superior }\end{array}$ & $\begin{array}{l}46 \\
38\end{array}$ & & $\mathrm{~T}_{9-10}$ & 86 & & 78 & \\
\hline $\begin{array}{l}\mathrm{T}_{10} \text { inferior } \\
\mathrm{T}_{11} \text { superior }\end{array}$ & $\begin{array}{l}44 \\
32\end{array}$ & & $\mathrm{~T}_{10-11}$ & 74 & & 72 & \\
\hline $\begin{array}{l}\mathrm{T}_{11} \text { inferior } \\
\mathrm{T}_{12} \text { superior }\end{array}$ & $\begin{array}{l}38 \\
34\end{array}$ & & $\mathrm{~T}_{11-12}$ & 76 & & 70 & \\
\hline $\begin{array}{l}\mathrm{T}_{12} \text { inferior } \\
\mathrm{L}_{1} \text { superior }\end{array}$ & $\begin{array}{l}28 \\
22\end{array}$ & & $\mathrm{~T}_{12}-\mathrm{L}_{1}$ & 51 & & 50 & \\
\hline Total & $438 / 2340$ & 18.1 & Total & $452 / 2340$ & 19.2 & $402 / 2340$ & 17.1 \\
\hline
\end{tabular}


were determined, the most common level was found to be the $T_{7-8}$ level $(n=17)$, followed by $T_{11-12}(n=7), T_{8-9}$ $(\mathrm{n}=4)$, and $\mathrm{T}_{10-11}(\mathrm{n}=4)$, respectively.

When 38 cases with single-level herniation were evaluated, the most common level was found to be the $T_{7-8}$ level $(n=15)$, followed by $T_{11-12}(n=6), T_{5-6}(n=3)$, $\mathrm{T}_{8-9}(\mathrm{n}=3)$ and $\mathrm{T}_{9-10}(\mathrm{n}=3)$, respectively.

The total number of cases with multi-level disc bulging/herniation was 115 (54 with multi-level bulging only, 31 with multi-level herniation only, and 30 with multi-level herniation accompanied with bulging). When 54 cases with multi-level bulging were evaluated, it was found that bulging was present at two levels in 30 cases, at three levels in 15 cases, at four levels in six cases, at five levels in two cases, and at seven levels in one case. When 31 cases with multi-level herniation were evaluated, it was found that herniation was present at two levels in 15 cases, at three levels in nine cases, at four levels in six cases, and at five levels in one case.

A total of 30 cases with multi-level bulging and herniation were evaluated. It was found that seven cases had single-level bulging and single-level herniation, six cases had bulging at one level and herniation at two levels, one case had bulging at one level and herniation at four levels, eleven cases had bulging at two levels and herniation at one level, one case had bulging at two levels and herniation at two levels, three cases had bulging at three levels and herniation at one level, and one case had bulging at four levels and herniation at one level. The frequency distributions of the disc levels according to single and multi-level pathologies are shown in Table 3.

When the disc degeneration and disc height loss at the thoracic level were evaluated, it was determined that among 195 cases (2,340 disc levels), 112 (57.4\%) cases had disc degeneration at 525 levels, and 104 (53.3\%) cases had loss of disc height at 387 levels. The levels at which the disc degeneration was present were $\mathrm{T}_{9-10}$, $\mathrm{T}_{8-9}, \mathrm{~T}_{10-11}, \mathrm{~T}_{7-8}, \mathrm{~T}_{11-12}$ levels, followed by $\mathrm{T}_{12}-\mathrm{L}_{1}$ and $\mathrm{T}_{6-7}$ levels, respectively. Similarly, the levels at which the disc height loss present were $\mathrm{T}_{9-10}, \mathrm{~T}_{10-11}, \mathrm{~T}_{8-9}$, $\mathrm{T}_{11-12}, \mathrm{~T}_{7-8}$ levels, followed by $\mathrm{T}_{12}-\mathrm{L}_{1}$ and $\mathrm{T}_{6-7}$ levels.

When evaluated regarding endplate degeneration and Schmorl node, it was determined that among 195 cases (2,340 disc levels), $102(52.3 \%)$ cases had Schmorl node at 438 levels (18.1\%). The frequencies of the Schmorl node and endplate degeneration at $\mathrm{T}_{9-10}$, $\mathrm{T}_{10-11}, \mathrm{~T}_{11-12}, \mathrm{~T}_{8-9}, \mathrm{~T}_{7-8}, \mathrm{~T}_{12}-\mathrm{L}_{1}$ levels were higher than those of the remaining levels, respectively (Table 4).
The Schmorl nodes were more common in 40-year and older age groups. However, there was no significant difference between male and female groups.

When the clinical findings were taken into consideration, 195 cases with disc pathologies were admitted with the complaint of dorsalgia. Neural compression findings were identified in the remaining 39 cases. When these cases were evaluated, it was found that seven cases had herniation and narrow channel at seven levels, five cases had herniation at three levels, five cases had herniation at one level, three cases had sequestered disc at one level, six cases had herniation at two levels, eight cases had multi-level herniation and bulging, and five cases had multi-level bulging.

\section{DISCUSSION}

This retrospective study included a total of 2,340 thoracic intervertebral disc levels in 195 patients in whom MRI examination was performed for the complaint of dorsalgia. Magnetic resonance imaging has been considered to be an ideal technique for the assessment of thoracic disc problems, since it is both non-invasive and very delicate. The obtained coronal, axial and sagittal images can precisely show the level and morphology of the herniations and also identify the intradural and free migrating disc fragments with the created adverse effects on the adjacent structures, particularly the spinal cord. ${ }^{[5,6]}$

In the literature, the majority of thoracic disc herniations were reported to be seen during the third to fifth decades. ${ }^{[1]}$ Our finding was, however, inconsistent with to a certain degree, and the majority of our patients belonged to the second to fourth decades. This result might have been caused by the difference of indications among the studies: our indication was dorsalgia and MRI were more widely used, compared to other studies in which MRI was used more likely, when thoracic disc degenerative pathology was suspected due to the presence of neurological symptoms. ${ }^{[12]}$

In our study, the most frequent findings on MRI were degeneration, height loss, bulging and herniation of the discs. Bulging and herniation were identified most frequently (69\% and $67 \%$, respectively) at the lower segments, from $\mathrm{T}_{7-8}$ to $\mathrm{T}_{11-12}$. A study performed on 40 cases revealed 49 thoracic disc herniations, which were predominantly present at the mid to lower segments with a ratio of about $75 \% .^{[8,13]}$ In our study, we found a similar result and revealed that two-thirds of the occurrences of disc bulging and herniation took place at $\mathrm{T}_{7-8}$ to $\mathrm{T}_{11-12}$. This finding can be explained by the anatomical differences between the ribs and their 
attachments. $T_{7-8}$ is the last level of individually fused ribs, $8^{\text {th }}, 9^{\text {th }}$, and $10^{\text {th }}$ ribs join the sternum as fused ribs and $11^{\text {th }}$ and $12^{\text {th }}$ ribs do not have any attachments to the sternum. This anatomy leads to increased flexibility of these intervertebral levels, compared to the higher thoracic levels. ${ }^{[1]}$ In our study, in 50-year old and younger age group, the most affected levels were $\mathrm{T}_{6-9}$, but in older age group, the most affected levels were $\mathrm{T}_{10-12}$. We estimate age-related changes of the vertebral colon and ligaments facilitate disc pathologies of the lower thoracic level. At younger age group, presumably, acute course such as trauma, malposition facilitates disc pathologies of the middle thoracic level. The affected levels of disc pathologies may result from these two different mechanisms.

Furthermore, in younger age group, disc degeneration and disc height loss coexistence with the same level of bulging and herniation were less common. We concluded that, in the young age group, the reason of the disc bulging and herniation was related with acute pathology and acute trauma. In older age groups, there was a correlation between degenerative signal loss, disc height loss, and disc bulging/herniation.

One of the significant findings of this study was that $20 \%$ of the cases had herniations at more than one level. This incidence was similar to the result of $26 \%$ reported by Linscott and Heyborne ${ }^{[2]}$ McInerney and Ball, ${ }^{[1]}$ in their review article about the pathophysiology of thoracic disc disease, suggested that there was a tendency for thoracic disc herniation to be multiple in nature and that they were commonly identified in cases with cervical or lumbar disc herniations. $^{[1,2]}$ However, this suggestion was not supported by many researchers. Our results and also Linscott and Heyborne, ${ }^{[2]}$ results were higher than those mentioned in previous studies..$^{[4,14-16]}$

Degenerative disc disease was present in 22\% $(525 / 2,340)$ of the levels, whereas loss of disc height was determined in $17 \%(387 / 2,340)$. The findings related to the incidences and locations of the degeneration and the loss of disc height were in accordance in our study sample, both being more frequent at lower thoracic intervertebral disc levels. Since degenerative etiology has been favored for disc herniation and bulging, ${ }^{[1,13,14]}$ the levels of disc degeneration and loss of height and herniation are expected to be similar. Our findings supported this expectation. When the incidence of degenerative disc disease was searched for in the literature, a wide range between 14 and 73\% was determined to be reported even in asymptomatic individuals. ${ }^{[6,8]}$ Our results were toward the smaller range.
The most commonly affected sites regarding the presence of both the Schmorl nodes and the endplate degenerations were the lower thoracic intervertebral levels in our series. The formation and clinical significance of the Schmorl nodes have not been clarified completely. The original report stated that they occurred with the disruption of the cartilaginous endplate of the vertebral body. ${ }^{[13,14]}$ It has also been indicated that their presence is correlated with disc space loss, but not with advanced degeneration of the disc. ${ }^{[13]}$ Our results favored the suggestion made by the original report, since the intervertebral levels of both findings were in correlation with each other.

Regarding the presence of neurological findings in cases with degenerative disc pathologies, the incidence of $20 \%$ is less than the $42 \%$ incidence reported in the study performed by Linscott and Heyborne ${ }^{[2]}$ Even with such a high incidence of neurological findings, they still suggested that the thoracic intervertebral disc herniation may remain a misdiagnosis. The degenerative disc pathologies were able to be diagnosed in our series by keeping the indication range of MRI wide to include all cases with dorsalgia, and by focusing on the status of the intervertebral discs in the interpretation of MRI retrospectively. We can also suggest that thoracic intervertebral disc herniation may remain a missed diagnosis, if it is not considered within the range of preliminary diagnoses in cases with dorsalgia. ${ }^{[16-20]}$

In conclusion, several conclusions may be made regarding the MRI findings in patients with dorsalgia. Magnetic resonance imaging is a precise imaging technique for investigating patients with complaint of dorsalgia. Using the MRI technique more widely, the disc pathologies may be diagnosed at earlier ages. Bulging, herniation, degenerative changes, endplate changes, and Schmorl nodes are more frequently located in the lower intervertebral levels. Multiple presences of herniations or bulging in one patient are more common than previously reported. Finally, the thoracic intervertebral disc herniation may present a significant diagnostic challenge and may remain a misdiagnosis, if it is not considered within the range of preliminary diagnoses in cases with dorsalgia.

\section{Declaration of conflicting interests}

The authors declared no conflicts of interest with respect to the authorship and/or publication of this article.

\section{Funding}

The authors received no financial support for the research and/or authorship of this article. 


\section{REFERENCES}

1. McInerney J, Ball PA. The pathophysiology of thoracic disc disease. Neurosurg Focus 2000;9:1.

2. Linscott MS, Heyborne R. Thoracic intervertebral disk herniation: a commonly missed diagnosis. J Emerg Med 2007;32:235-8.

3. Cornips EM, Janssen ML, Beuls EA. Thoracic disc herniation and acute myelopathy: clinical presentation, neuroimaging findings, surgical considerations, and outcome. J Neurosurg Spine 2011;14:520-8.

4. Russell T. Thoracic intervertebral disc protrusion: experience of 67 cases and review of the literature. Br J Neurosurg 1989;3:153-60.

5. Vanichkachorn JS, Vaccaro AR. Thoracic disk disease: diagnosis and treatment. J Am Acad Orthop Surg 2000;8:159-69.

6. Wood KB, Garvey TA, Gundry C, Heithoff KB. Magnetic resonance imaging of the thoracic spine. Evaluation of asymptomatic individuals. J Bone Joint Surg [Am] 1995;77:1631-8.

7. Singounas EG, Kypriades EM, Kellerman AJ, Garvan N. Thoracic disc herniation. Analysis of 14 cases and review of the literature. Acta Neurochir (Wien) 1992;116:49-52.

8. Girard CJ, Schweitzer ME, Morrison WB, Parellada JA, Carrino JA. Thoracic spine disc-related abnormalities: longitudinal MR imaging assessment. Skeletal Radiol 2004;33:216-22.

9. Kasch R, Mensel B, Schmidt F, Drescher W, Pfuhl R, Ruetten S, et al. Percutaneous disc decompression with nucleoplasty-volumetry of the nucleus pulposus using ultrahigh-field MRI. PLoS One 2012;7:41497.

10. Shirzadi A, Drazin D, Jeswani S, Lovely L, Liu J. Atypical presentation of thoracic disc herniation: case series and review of the literature. Case Rep Orthop 2013;2013:621476.
11. Fardon DF, Williams AL, Dohring EJ, Murtagh FR, Gabriel Rothman SL, Sze GK. Lumbar disc nomenclature: version 2.0: Recommendations of the combined task forces of the North American Spine Society, the American Society of Spine Radiology and the American Society of Neuroradiology. Spine J 2014;14:2525-45.

12. McInerney J, Ball PA. The pathophysiology of thoracic disc disease. Neurosurg Focus 2000;9:1-8.

13. Pfirrmann CW, Resnick D. Schmorl nodes of the thoracic and lumbar spine: radiographic-pathologic study of prevalence, characterization, and correlation with degenerative changes of 1,650 spinal levels in 100 cadavers. Radiology 2001;219:368-74.

14. Yue B, Chen B, Zou YW, Xi YM, Ren XF, Xiang HF, et al. Thoracic intervertebral disc calcification and herniation in adults: a report of two cases. Eur Spine J 2016;25:118-23.

15. Arnold PM, Johnson PL, Anderson KK. Surgical management of multiple thoracic disc herniations via a transfacet approach: a report of 15 cases. J Neurosurg Spine 2011;15:76-81.

16. Giblin EM, Hochheiser GM. Thoracic disk herniation resulting in acutely progressing paraplegia in a pediatric patient. Pediatr Emerg Care 2008;24:550-3.

17. Reynolds JM, Belvadi YS, Kane AG, Poulopoulos M. Thoracic disc herniation leads to anterior spinal artery syndrome demonstrated by diffusion-weighted magnetic resonance imaging (DWI): a case report and literature review. Spine J 2014;14:17-22.

18. Zhang C, Xue Y, Wang P, Yang Z, Dai Q, Zhou HF. Foot drop caused by single-level disc protrusion between T10 and L1. Spine (Phila Pa 1976) 2013;38:2295-301.

19. Lara FJ, Berges AF, Quesada JQ, Ramiro JA, Toledo RB, Muñoz HO. Thoracic disk herniation, a not infrequent cause of chronic abdominal pain. Int Surg 2012;97:27-33.

20. Baranto A, Börjesson M, Danielsson B, Hellström M, Swärd L. Acute chest pain in a top soccer player due to thoracic disc herniation. Spine (Phila Pa 1976) 2009;34:359-62. 